\title{
The Effect of Lime on Organic Soils Stabilization
}

\author{
Pouya Javadzadeh \\ Department of Geotechnical Engineering, Faculty of Civil Engineering, \\ University of Tabriz, Tabriz, Iran \\ Email: py.javadzadeh@gmail.com . https://orcid.org/0000-0003-1701-8170
}

\begin{abstract}
Organic soils or soils with an organic content have been used with varying content of organic matter as concepts with different meanings in geotechnical engineering. These soils are decomposed nonliving organic matter such as plant and animal remains, and this decomposition process is mainly influenced by bacterial activity, hot weather, good humidity and oxygen accessibility. In this study, lime was added in soils with organic content to examine their effects on soil shear strength. Different percentages of sand, clay, and peat have been used in this study. In this study, different percentages of lime $(4 \%, 6 \%)$ have been used for soil stabilization. The curing times for this study are 3 days, 7 days, 28 days. Finally, after performing the necessary tests on soil shear strength and comparing the effects of lime in soils with organic content, little effect of lime on increasing the strength of soils with organic matter was observed.
\end{abstract}

Keywords: Chemical Remediation and Stabilization, Lime, Shear Strength, Peat (Organic Matter)

\section{Introduction}

Reducing the high-quality land in large cities and the need to expand new areas lead to apply unsuitable land with unfavorable technical specifications. Some of these unsuitable soils are natural deposits that have not withstood large and heavy loads during the formation process in the presence of young geological organic matter; therefore, they have low shear strength and creep potential and very high compressibility. By constructing heavy foundations, earth dams and bulky structures on these soft soils with high compaction, no acceptable result is achieved and causes many different settlement, multiple cracks, changing the slope of pavements during operation and use of various thick and costly substrate layers at the execution time.

Organic matter in the soil consists of decomposed plant and animal residues at different levels resulting from their chemical and biological decomposition. The main source of soil organic matter is plant fibers. Decomposed animals and their residue are secondary source of organic matter.

Organic soils are found in many parts of Europe and in some parts of Iran and consist a range of clay with low organic content to peat (completely organic soils). In clays with organic content, organic matter is irregularly placed in the pores of soil minerals and then accumulated. These colloidal particles accumulated with the mineral reduce permeability and in some cases increase the tendency to creep. Engineering problems in these soils are similar to the problems in soft clay soils, their problems are high compressibility, high creep effects, effective stresses and very low strength and in some cases very low permeability.

There are some little guidelines for defining and linking soils to known groups. Discarding the details given by various researchers, organic soils can be divided into the following main groups:

1. A small part of organic soils such as peat and Gyttija that are completely and purely organic.

2. A larger part of organic soils include soils that have been combined with mineral soils during the transition and deformation stage such as clayey Gyttija, clay with organic content and floodplain sediments.

3. Sulfide-rich soils mainly contain sulfide-rich silt such as bog soils, sludge and swamps.

4. Surface soils that contain percentages of organic matter.

5. By slightly expanding the boundaries of organic soils, calcium carbonate-rich sediments such as bog lime and soils with silica wall like diatom include in the organic soils classification.

Bog lime often forms in areas with calcareous bedrock in the vicinity of peat deposits. Due to the formation of calcareous soils by mechanical accumulation and deposition of water-soluble calcium and iron-bearing compounds solely or utilizing organisms, these soils have been placed in the group of somewhat organic soils.

Various scientific and experimental methods are used to stabilize soils with organic content; (superficial stabilization) and (deep stabilization) are more common methods. In deep stabilization, columns of soil are stabilized to the required depth and increase the bearing capacity. These columns sometimes thicken and increase the strength of the surrounding soil by reducing the percentage of water in the soil. In this method, the reactions performed between the stabilizing materials (lime, cement, gypsum) and the soil increase the shear strength and the compressive modulus of the stabilized columns, by producing hard cementitious materials. Increasing the 
compressive modulus in these columns modifies the compressibility properties, increases the shear strength and reduces the settlement in the adjacent organic soils.

In superficial stabilization, the entire soil volume is modified by mixing with stabilizing materials. In order to achieve the desired results in the above methods, it is necessary to investigate the chemical and physical reactions of organic soils of stabilizing materials in the laboratory through scientific and experimental methods. This study is based on several perspectives. The success rate of the stabilization process in executive projects depends on accurate and coherent laboratory studies and the design of suitable mixtures of lime and soil.

The study of engineering resources in recent years mainly focuses on the use of calcium stabilizers in soils with organic content; a group of researchers recommended lime, cement or a combination of cement with other stabilizers such as lime, slag, gypsum and fly ash for stabilizing soils with organic content.

Preliminary studies show that lime is one of the most effective and common chemical stabilizers in soils with high swelling and high plastic characteristics. Lime alone can be a successful stabilizer for soils with high finegrained contents. Addition of lime to fine-grained soils causes positive ion exchange reaction, flocculation reaction and pozzolanic reaction. These chemical interactions have important effects on the technical characteristics of soils and causes remediation of fine-grained soils.

In chemical stabilization, chemical additives such as lime, cement, polymer, sulfur, calcium chloride, coal ash and slag from smelting furnaces due to chemical interactions with the soil stabilize and modify the technical characteristics of the soil. In the clay soils remediation, lime and cement are among the most widely used and effective materials. The strength of clay-cement-stabilized clays is mainly due to chemical reactions, the strength of which is controlled by factors such as the type of clay mineral, the amount of organic matter and soil $\mathrm{pH}$ [1].

The mechanism of soil stabilization with lime and cement was proposed more than 40 years ago by Ads et al. (1962), Moh (1962), Meteos (1964), Thomson (1966), etc. [citing source number 1]. In addition to stabilizing the surface layers of the soil, deep soil layers are also possible by installing equipment by deep mixing with lime or cement, this method is based on the mechanism and behavior of soft soils stabilized with lime or cement. The use of industrial wastes such as cement slag and cement fly ash along with lime or cement has been suggested by many researchers such as Kamia et al. (1993), Yoshida (1998) [citing source 1]. The success rate of the stabilization process depends on factors such as the percentage of soil organic matter, the concentration of salts in the soil, bacteria, microorganisms (control the degree of alkalinity) and the composition of clay minerals [1].

Lime curing is an old technique and the history of these studies dates back to the 1950s. Lime can be used alone or in combination with other materials to cure a wide range of soils.

The properties of minerals in the soil determine the rate of reaction of lime with the soil and the final strength of the stabilized layer. Generally, fine-grained clay soils (at least $25 \%$ passing through sieve number 200 and plastic index greater than 10) are successful in stabilization with lime. Often 3-6\% by weight of lime is enough to stabilize these soils. In general, soils that are in the Unifide classification in groups SC, SM, GC, SW-SC, SP-SC, GWGC, CH GM-GC, CL, MH or in Ashto classification in groups A-2, A -4, A-5, A-6, A-7, A-2-6, have the ability to stabilize with lime [2]

The result of the reactions of lime with soil can be divided into the following three parts:

Drying the soil

During this reaction, the soil moisture dries quickly. The drying effect is one of the most widespread applications of lime at construction sites which enabling the contractor to compact the soil within a few hours, while waiting for the soil to dry due to natural evaporation may take days. Generally, (1-4) percent of lime will be sufficient for this purpose [2].

Temporary modification of soil properties

These changes occur within 1 to 48 hours after mixing lime with soils with a high percentage of clay and modify soil engineering properties. This modification can be permanent or temporary. Some of these modifications are as follows:

-Decreased soil plastic index

-Increase optimal soil moisture

-Reduced maximum dry soil density

-Modify soil compressibility

-Reduce the potential for swelling and shrinkage of the soil

-modifying soil strength and stability after compressing

Lime used for temporary soil remediation is the percentage by weight of the soil, which is generally less than the amount used for permanent soil remediation. 
In soils with less fine grains and if lime alone does not react significantly with the soil, pozzolans such as fly ash and slag, which contain silica and alumina can be used. By properly combining pozzolans with lime, all types of soils can be stabilized or temporarily modified.

Soils that contain significant amounts of organic matter (more than $2 \%$ ) or sulfate (more than $0.3 \%$ ) may require higher amounts of lime [2].

In general, soil remediation with lime is mainly done with the aim of modifying the properties of the soil and bringing these properties to the desired values. These goals mainly include increasing the strength and loadbearing capacity of soil, increasing soil strength against cracking, fatigue and permanent deformation, modifying soil modulus properties, reducing swelling and shrinkage in soils, and increasing long-term soil strength against freezing or moisture changes.

The relative intensity of reactions between fine-grained soils and lime depends on the physical and chemical properties of soils, especially the type of clay minerals, replaceable sodium ions, combinable iron, silica to alumina ratio and soil weathering, soil sulfate content and especially organic matter content. Soils that contain more than $2 \%$ organic matter or more than $0.3 \%$ sulfate may require more lime, special mixing and processing procedures. A group of organic matter has an adverse effect on pozzolanic reactions by adsorbing calcium cations in the stabilization process, delaying the hardening of soil and stabilizing mixtures [3]

Some other organic materials slow down the resistance processes by forming insoluble products in reaction with $\mathrm{Ca}(\mathrm{OH}) 2$ (hydrated lime) or by lowering the $\mathrm{pH}$ and have an adverse effect on the stabilization process. Due to the unpredictability of the properties of organic deposits, it is a little difficult to estimate the engineering parameters, and this makes it impossible to discuss the appropriate type and amount of stabilizer with a general statement. Therefore, the rate of soil modification and remediation depends on the properties of soil organic particles.

In most cases, the disappearance of the stabilizing material during the stabilization process has led to poor support of roads, slopes, and retaining walls, identify the problematic part of organic matter that causes deficiencies in stabilization with lime and clarifying the mechanisms that are responsible for the intervention of organic matter in the process of stabilization with lime, and further study of the process of stabilization of organic soils are necessary. In this study, the effect of lime stabilization in organic soils was investigated.

\section{Materials and methods}

\section{Consuming materials}

Clay: In the classification of soils, clay is a fine-grained soil. Clay particles are usually defined as smaller than $0.002 \mathrm{~mm}$. However, sometimes particles with a size of 0.002 to $0.005 \mathrm{~mm}$ may also be defined as clay. Particles that are in the clay class by size do not necessarily contain clay minerals.

Sandy soil: The shape of coarse grains in a soil has a significant effect on soil engineering properties. Sand, soil is prepared from Emamieh sand washing in Tabriz, on which granulation test has been performed based on ASTM D 422-87 method. And the sandy soil is mostly fine sand.

Peat soil: Organic matter in the soil, consists of mixtures composed of degraded residues of plants and animals at different levels and materials obtained from their chemical and biological decomposition. To obtain organic matter, dry oxidation test or LO1 method has been used, which is performed in accordance with ASTM D 2974. After the relevant experiment, the amount of organic matter in peat soil was calculated to be about $95.71 \%$. The peat used in this study is from lith peat factory of Lithuanian company.

\section{Soil}

In this research, three types of soil composition have been used, which are named with $\mathrm{A}, \mathrm{B}$ and $\mathrm{C}$. The composition is selected in such a way that the soil from $\mathrm{A}$ to $\mathrm{C}$ is gradually reduced from the amount of coarse grain and increased to the amount of fine grain. [Table 1]

Table 1- Soil Classification

\begin{tabular}{|c|c|c|c|}
\hline Soil & Peat & Clay & Sand \\
\hline A & $4 \%$ & $16 \%$ & $80 \%$ \\
\hline B & $7 \%$ & $28 \%$ & $65 \%$ \\
\hline C & $10 \%$ & $50 \%$ & $40 \%$ \\
\hline
\end{tabular}


Stabilizing material

Lime

Lime is produced by cooking limestone (calcium carbonate) with impurities such as magnesium, iron, sulfur, etc. and has different types, the most common of which are:

1) Quicklime or (CAO)

2) slaked lime or $\mathrm{CA}(\mathrm{OH}) 2$

3) Dolomite quicklime ( $\mathrm{CAO}+\mathrm{MGO})$

4) Dolomite slaked lime $(\mathrm{MG}(\mathrm{OH}) 2)$ or $((\mathrm{CAO}(\mathrm{OH}) 2)$

By burning limestone in furnaces at a temperature of $980^{\circ} \mathrm{C}$, calcium carbonate is decomposed into calcium oxide and carbon dioxide. The formed calcium oxide is called quicklime.

$\mathrm{CACO}_{3}$ heat $\longrightarrow \mathrm{CAO}+\mathrm{CO}_{2}$

Quicklime is a whitish substance with a melting point of between 2580 and $2750^{\circ} \mathrm{C}$. The specific gravity of quicklime is between 3.1 to 3.3 grams per cubic centimeter. Lime reacts with water and converted to calcium hydroxide by releasing large amounts of heat. By the above action, quicklime is converted into slaked lime, which is in the form of powder.

$\mathrm{CAO}+\mathrm{H}_{2} \mathrm{O} \longrightarrow \mathrm{CA}(\mathrm{OH})_{2}$ + heating

Quicklime has a larger volume change than slaked lime. On average, the volume change of quicklime is 2.5 to 3 times greater than slaked lime. The conversion of quicklime to slaked lime is done with a change in its specific gravity, so that after flowering its specific gravity is reduced to about 2.2 to 2.4 grams per cubic centimeter. Slaked lime has less moisture absorption than quicklime and therefore is easier to work, store and maintain.

Lime is mainly suitable for stabilizing fine-grained soils with a plastic index greater than 10 and very plastic clay soils. Lime is not suitable for stabilizing soils containing more than two percent organic matter and also more than half a percent water-soluble sulfate. In general, soils that are in the Unified classification in the groups SP-SC, CH-, CL, MH, GW-GC, GP-GC, GM-GC, SM-SC, SC, SM, SW-SC or in the classification Ash to are in groups A4-A5-A6-A7 and A2, they can be stabilized with lime. Experience has shown that soils with a pH of less than 7 or containing more than one percent of carbonaceous organic matter do not react well with lime. The lime used in this research is quicklime which has been prepared from Azar lime Company of Tabriz, Iran .

\section{Granulation test}

\section{Tests performed:}

The granulation test was performed according to ASTM D422-87 standard. This test is useful for predicting soil water movement, soil permeability, and capillary properties, use of filtration and drainage, and soil sensitivity. Granulation is usually done by two methods, sieving granulation and hydrometric granulation. Since the soil used is a combination of several soil types and its coarse grains are in the majority, so the sieving granulation experiment has been used.

\section{Density test}

This test is performed according to ASTM 698-78. The purpose of compaction testing is to reduce soil porosity. The presence of water to a certain extent facilitates this operation. Obtaining the maximum moisture content and specific gravity of the soil after applying a certain amount of percussion energy is an important goal of density testing.

\section{Atterberg Limits}

The test was performed according to ASTM D4318-87 standard. The purpose of this experiment is to determine the liquid and the plastic limit of the soil. Fine-grained soils take on different states as the amount of water absorbed increases. The soil liquid limit (LL) of the soil is 50, so the clay is CL .[ Table 2]

PI: Plastic Index

$\mathrm{PI}_{\mathrm{A}}$ : Plastic Index of Line A $\longrightarrow \mathrm{PI}=0.9(\mathrm{LL}-20)$

PL: Shrinkage Limit

Table 2 - Numbers obtained from the Atterberg Limits

\begin{tabular}{|c|c|c|c|}
\hline $\mathrm{PI}$ & $\mathrm{PI}_{\mathrm{A}}$ & $\mathrm{LL}$ & $\mathrm{PL}$ \\
\hline 25 & 21.9 & 50 & 25 \\
\hline
\end{tabular}


GS test (specific density)

This test is performed according to ASTM D 854-10 standard. The purpose of this experiment is to determine the ratio of specific gravity of soil to specific gravity of water. Weights per unit (density) of each soil are used in issues such as settlement and stability in soil engineering. The test was performed by method (b) for the wet sample and this test was performed on soils A, B and C, which are shown in Table 2,3.

Table 3- Results of Gs soils

\begin{tabular}{|c|c|}
\hline Soil & Gs \\
\hline A & 1.893 \\
\hline B & 2.07 \\
\hline C & 2.5 \\
\hline
\end{tabular}

Hydrometric test

The hydrometric method is one of the most common methods for estimating the particle size passed through the 200 sieve. The obtained data are shown on a semi-logarithmic diagram. In hydrometric test, the relationship between the average velocity of spherical particles in liquid, the particle diameter, the specific gravity of a liquid, and fluid of viscosity known as Stokes' law are used.

Due to the fine-grained nature of the soil studied in this study, hydrometric method was used to granulate this soil and the curve is shown in Figure 1. Also, the measured Gs for the clay used in the experiments is 2.7.

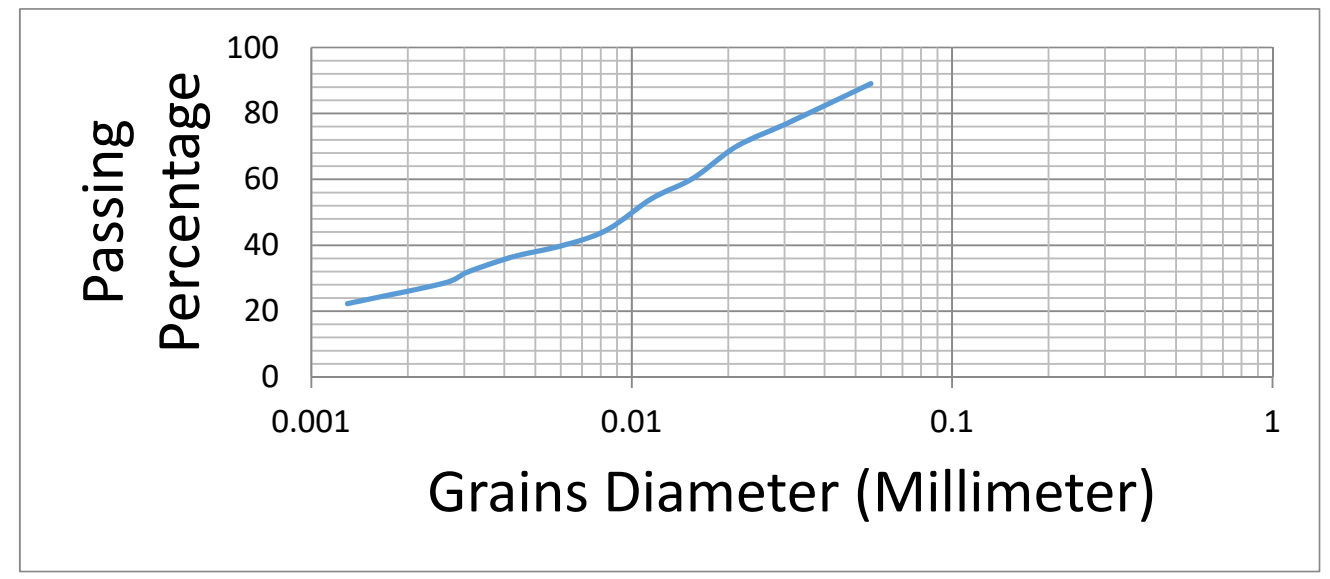

Figure 1. Hydrometric test curve

\section{Direct Shear Test}

This test is performed based on Standard ASTM D 3080-90. In this test, by moving the upper half of a box containing soil proportional the lower half, the soil inside the box is objected under the shear stress to be disjointed. The top of the box is displaced to the bottom and cutting the soil sample in one direction is done.

If the cross section under the shear force has an area equal to $\mathrm{A}$, we have:

Shear Stress $=\frac{\text { Shear Force }}{A} \quad$ gertical Stress $=\frac{\text { Vertical Force }}{A}$

Shear strength is the amount of stress required for slip on a grain surface:

$$
\tau=\sigma \tan \phi+C
$$

In this equation, $\mathrm{C}$ is the adhesion and $\phi$ is the internal friction angle. The above equation is known as the MoherColumbian failure criterion.

In direct shear test, one of the two methods of stress control test or strain control test can be used for loading. In a stress control test in which the shear force is applied by a constant weight and the amount of strain is measured. In a strain control test, the rate of deformation or strain is constant and the amount of shear force is measured. Shear test was performed on soils produced (A, B, C) with sodium silicate as well as samples stabilized with lime. Sodium silicate with percentages $(5 \%, 9 \%, 12 \%, 15 \%)$ and lime with percentages $(4 \%, 6 \%)$ are combined with soils A, B and C. $6 * 2 * 6$ molds were used to prepare the samples. The samples were examined in $(3,7$ and 28 days). 


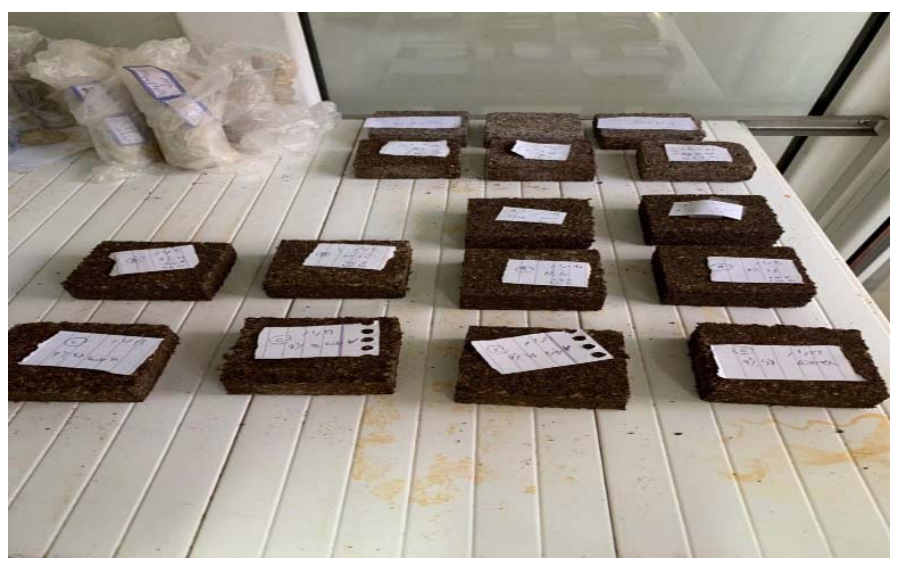

Piture1 - Direct shear test samples

In the preparation of samples, the water for the samples is based on the percentage of moisture in the density test. In samples containing lime, the optimum moisture content of each soil is the same as in the density test. Piture 1

\section{Findings}

Results of direct shear test with lime additive

Direct shear test was performed on three types of soils A, B and C with different grain size, and lime with $4 \%$ and $6 \%$ percentages was added to the three types of mixed soils to examine with maximum shear strength and comparing it with pure samples. (Without additive) on 3, 7 and 28 days.

Shear strength of soil A with lime additive: The percentages studied in this experiment are $4 \%$ and $6 \%$ of lime, which were tested with pure samples during of 3, 7, 28 days. [Table 4]

Table 4: Direct shear strength in kilograms per square centimeter $(\mathrm{Kg} / \mathrm{Cm} 2)$ in soil samples containing lime

\begin{tabular}{|c|c|c|c|}
\hline Material & $0 \%$ & $4 \%$ of Lime & $6 \%$ of Lime \\
\hline 3 Days & 3.9 & 3.23 & 3.36 \\
\hline 7 Days & 4.1 & 4.29 & 3.67 \\
\hline 28 Days & 4.29 & 4.11 & 4 \\
\hline
\end{tabular}

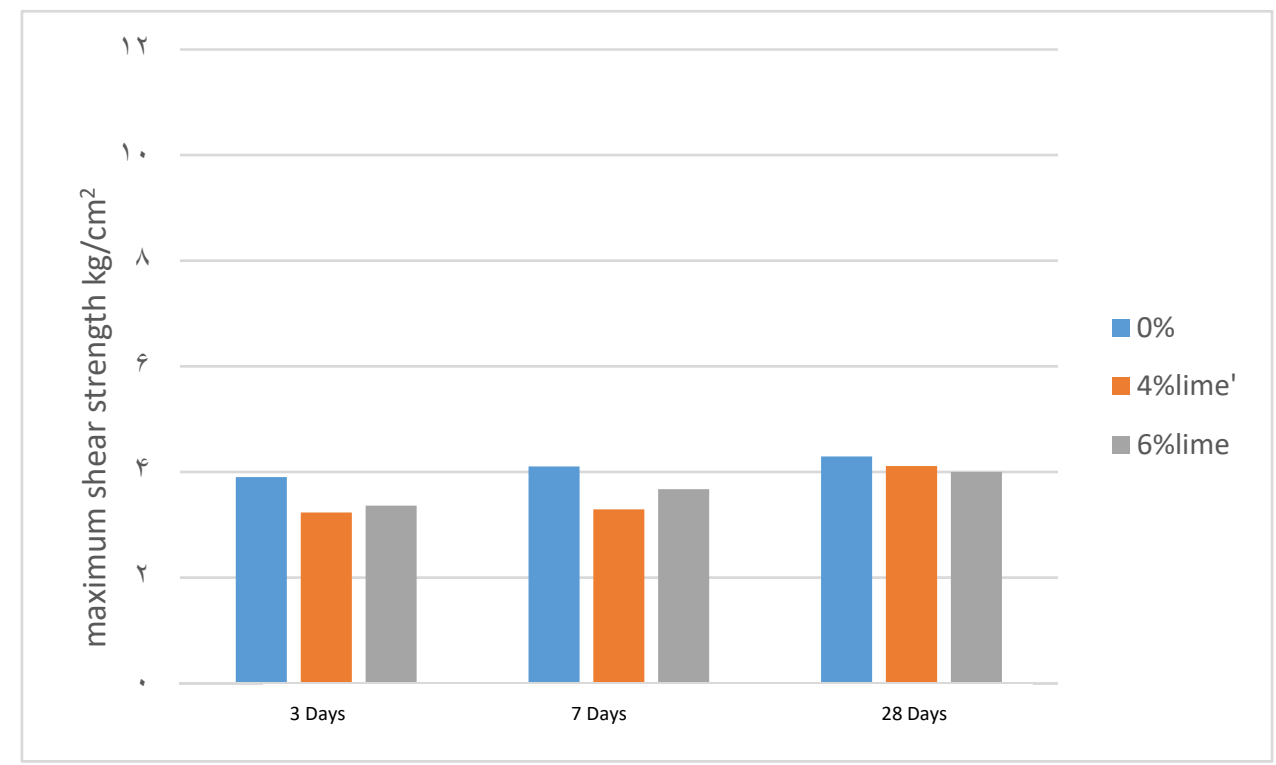

Figure 3 -Shear strength changes with changes in lime percentage at soil A over the time 
Figure 3 shows that the shear strength in 4\% lime samples did not change much on days 3 and 7, but increased over time at 28 days. However, in $6 \%$ and $4 \%$ lime samples, the strength was almost close to each other on days 3 and 7. In $4 \%$ lime, strength has a slightly higher than 6\% during 28 days, but it has less strength than its pure sample. It can be concluded that the effect of lime in soil A has increased over time compared to the pure sample, due to the coarse grain content in this soil that the main characteristic of the soil is reduced adhesion. Also, with increasing the percentage of lime from $4 \%$ to $6 \%$, the shear strength of 28 -day soil has decreased.

Shear strength of soil B with lime additive: The percentages studied in this experiment are $4 \%$ and $6 \%$ of lime, which were tested with pure samples during 3, 7, 28 days.

Table 5: Direct shear strength in kilograms per square centimeter $(\mathrm{Kg} / \mathrm{Cm} 2)$ in soil samples with lime

\begin{tabular}{|c|c|c|c|}
\hline Material & $0 \%$ & $4 \%$ of Lime & $6 \%$ of Lime \\
\hline Time & & & \\
\hline 7 Days & 4.76 & 3.9 & 4.76 \\
\hline 28 Days & 4.5 & 4 & 4.9 \\
\hline
\end{tabular}

According to Figure 4, the pure samples did not change much resistance over time. However, $4 \%$ of lime samples showed strength over time, but $6 \%$ of lime samples had high strength on days 3 and 7 , but with the change of time to 28 days, the shear strength decreased and became brittle. However, both $4 \%$ and $6 \%$ did not show an increase in strength compared to the pure soil, which can be attributed to the high coarse-fine soil sample. [Figure 4]

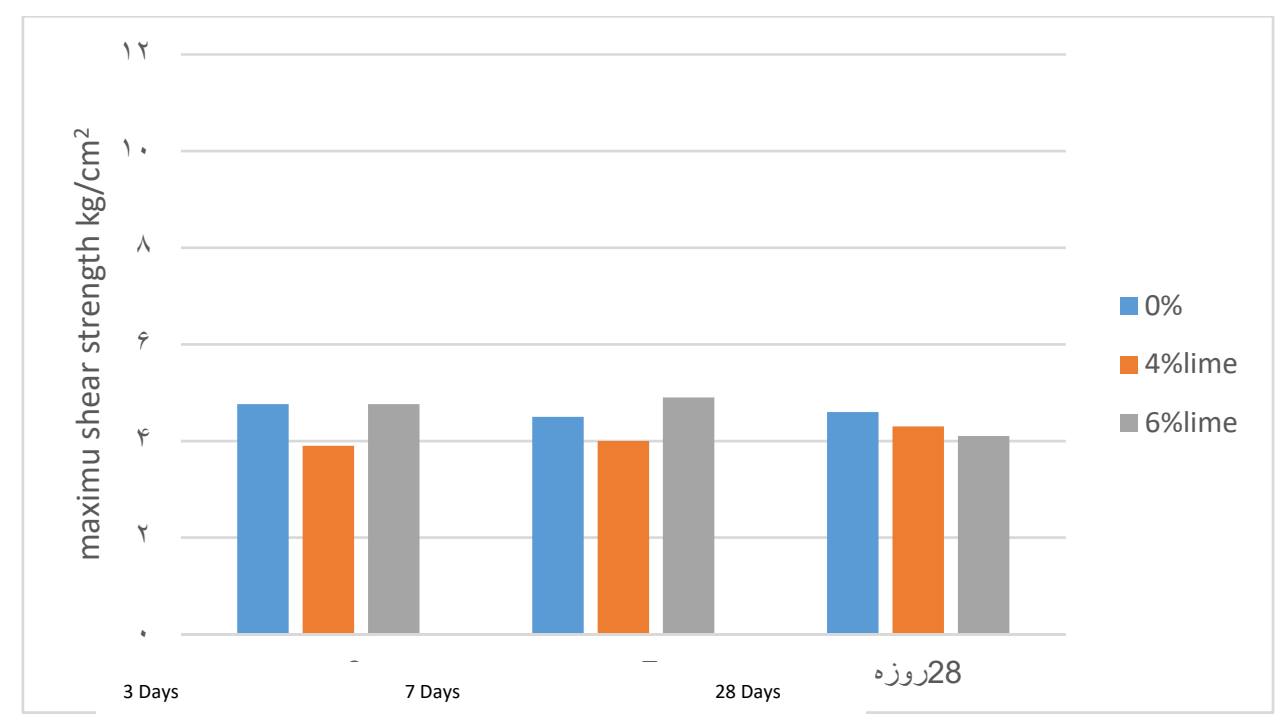

Figure 4- changes in shear strength with changes in soil lime percentage B over the time

Shear strength of soil $\mathrm{C}$ with lime additive: The percentages studied in this experiment are $4 \%$ and $6 \%$ of lime, which were tested with pure samples at intervals of 3, 7, 28 days. [Table 6]

Table 6- Direct shear strength in kilograms per square centimeter $(\mathrm{Kg} / \mathrm{Cm} 2)$ in soil samples with lime

\begin{tabular}{|c|c|c|c|}
\hline Material & $0 \%$ & $4 \%$ of Lime & $6 \%$ of Lime \\
\hline Time & & & \\
\hline 3 Days & 4.9 & 4.23 & 5.1 \\
\hline 7 Days & 4.6 & 4.59 & 5.2 \\
\hline 28 Days & 4.1 & 4.8 & 4.3 \\
\hline
\end{tabular}




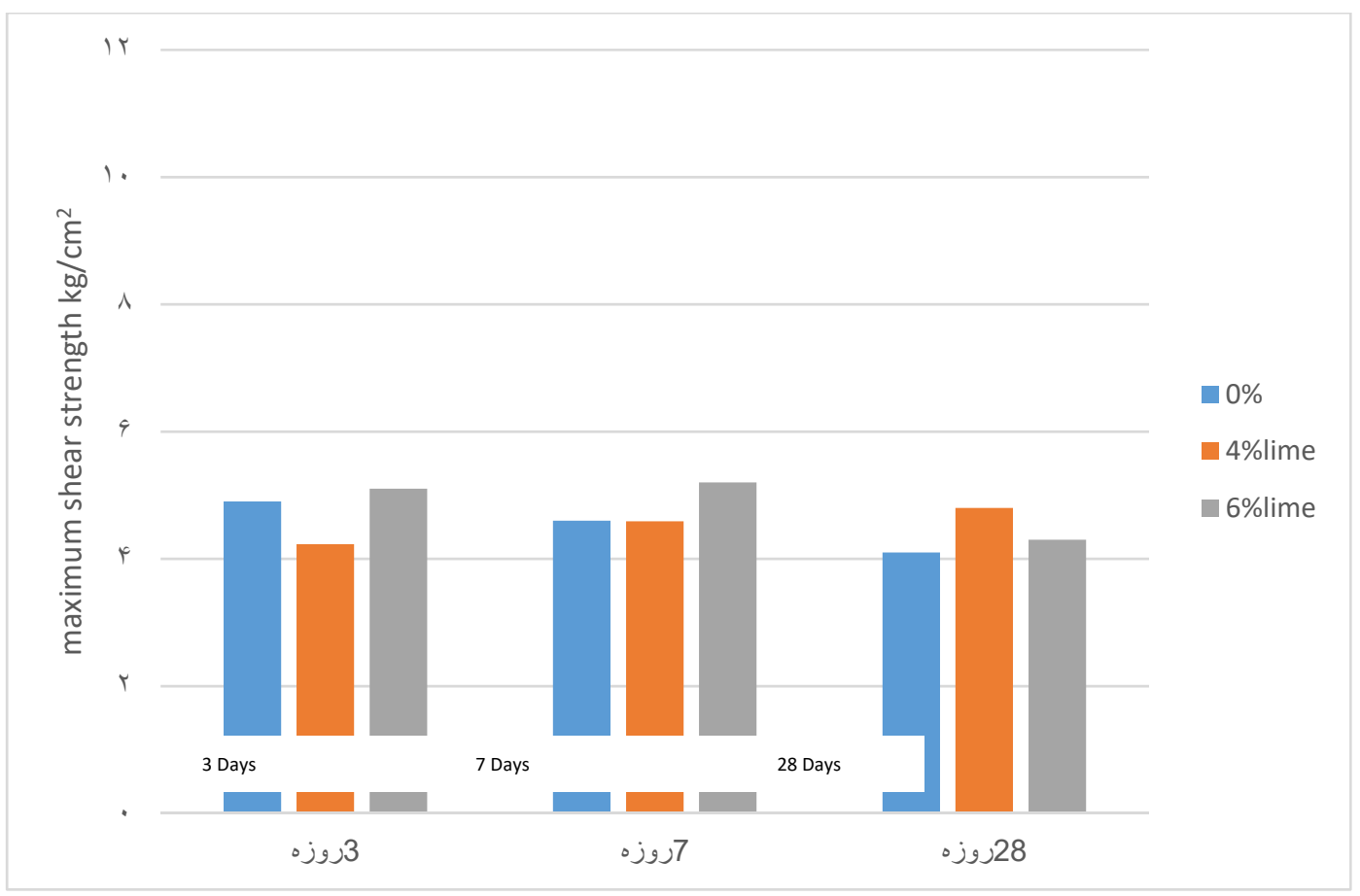

Figure 5- changes in shear strength with changes in soil lime percentage $\mathrm{C}$ with time change

Figure 5 shows the changes in shear strength with changes in soil lime percentage $\mathrm{C}$ over time. It can be seen that the pure soil $\mathrm{c}$ has its shear strength decreased over time. Also, 4\% lime had a slight increase in resistance with the change of time to 28 days. However, $6 \%$ of lime had an increase in strength on 3 and 7 days, but in 28 days it was associated with a decrease in shear strength, which increased compared to the previous two types of soil (A and $\mathrm{B}$ ). Due to the fact that soil $\mathrm{C}$ has a higher percentage of peat and clay than sand, fine grain has been more than coarse grain, which has caused a better effect of lime on the shear strength of soil. Due to the fact that increasing the amount of clay in a composite soil (peat-clay-sand) increases compaction, adding lime to the soil modifies the strength properties of soils with more fine grains, in the short term reduces swelling and reduces permeability. [Figure 6]
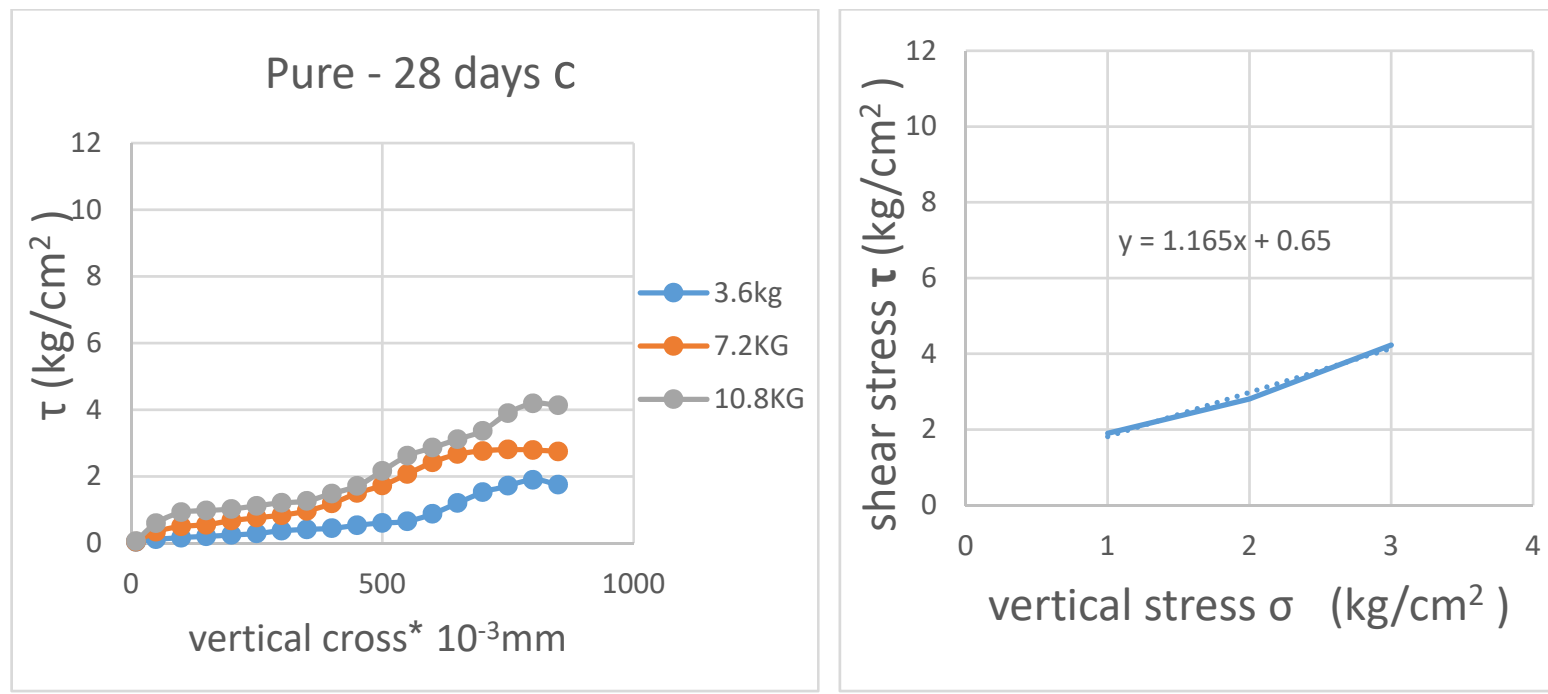

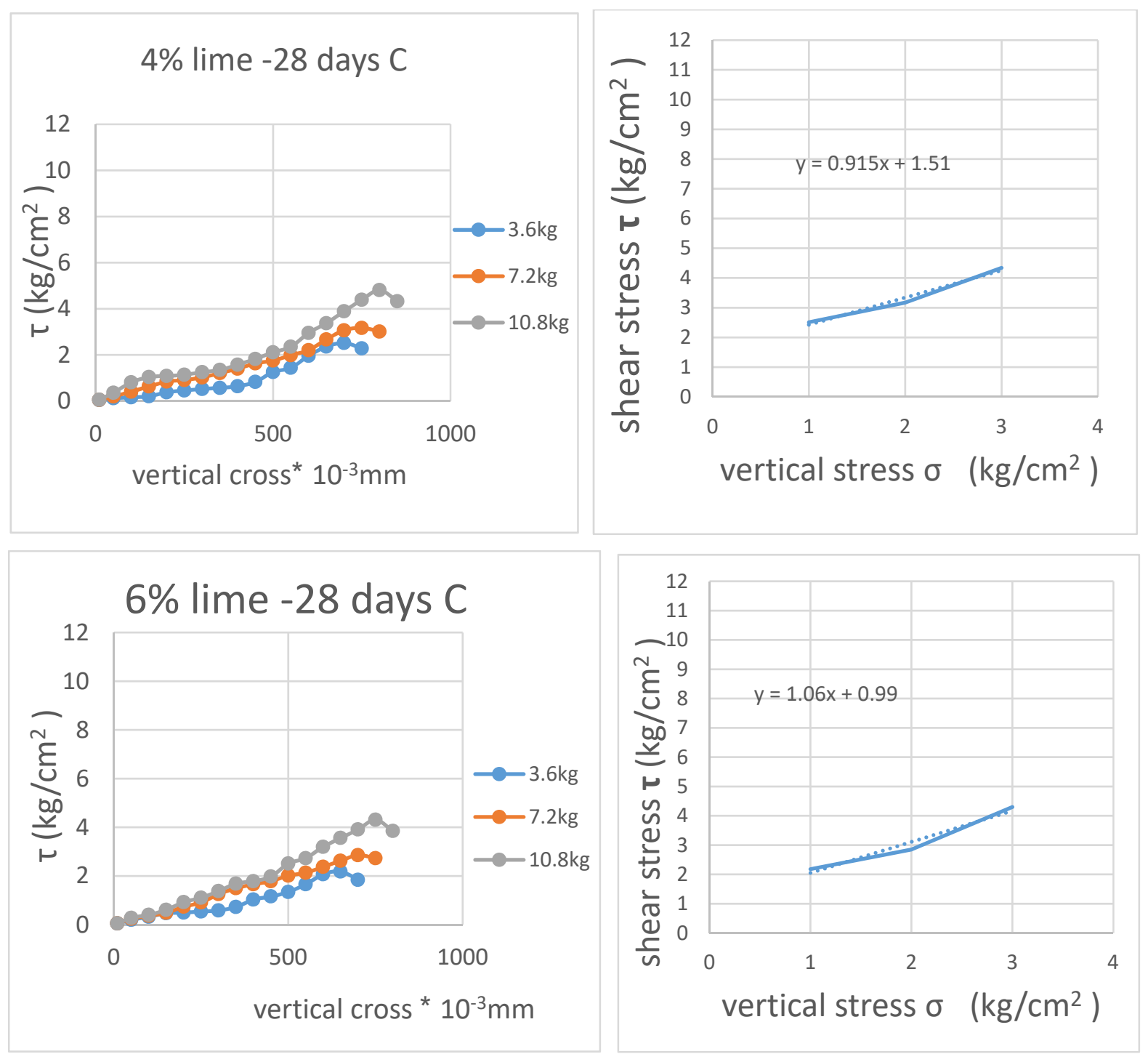

Figure 6 - 28-day lime stress in different percentages

\section{Conclusion}

The presence of organic matter in the soil composition for chemical, physical and biological reasons severely affects the engineering properties of the soil and reduces the strength properties of the soil. Most of the pavements, slopes and embankments on thin layers of organic soils, which are enclosed between the soil layers and have not been considered in the construction and design stages, have led to frequent settlement, multiple cracks and destruction over the years. The locals were paved and incurred huge costs for repairs and renovations. The effect of organic matter on soil properties varies greatly and depends on the rate of decomposition of organic matter, chemical composition, and percentage of organic matter, electric charge and cation exchange capacity of organic particles. The properties of organic soils are derived from their organic constituents.

According to the results of $4 \%$ and $6 \%$ lime in soil compositions A, B and C, shear strength in soils A and B has not changed much, but in soil $\mathrm{C}$ due to the fine-grained soil has shown its effect. The effect of lime was $4 \%$ to $6 \%$ slightly higher and increasing the percentage of lime does not help to modify the mechanical properties of the soil. According to the results of this research, it is suggested to address the following cases in further studies:

* Investigation of the effect of nanomaterials as a stabilizer in organic matter soils

- In this study, the soil is a combination of sand, clay and peat were used. It is suggested to use other soils such as bog lime and silt too.

\section{References}

[1] Koslanant, Sinat, (2006); Influence of storage conditions on geotechinical properties of ariake clay and on its chemical stabilization, A dissertation for the degree of doctor of Philosophy in geotechinical engineering, Saga University, Japan.

[2] National lime association (2004); lime-treated Soil Construction manual: lime stabilization \& lime moidification.

[3] Hartlen. J and Wolski, W (1996); Embankments of organic soils, ELSEVIER Sciences, Netherlans.

[4] The oxychem, sodium silicates handbook, Occidental Chemical Corporation,Dallas,2008 